\title{
Skeletal site-dependent response of bone mineral density and quantitative ultrasound parameters following a 12-month dietary intervention using dairy products fortified with calcium and vitamin $D$ : the Postmenopausal Health Study
}

\author{
George Moschonis and Yannis Manios* \\ Department of Nutrition and Dietetics, Harokopio University of Athens, 70, El.Venizelou Ave, \\ 17671 Kallithea, Athens, Greece
}

(Received 25 March 2006 - Revised 7 September 2006 - Accepted 11 September 2006)

\begin{abstract}
The aim of the current study was to examine whether calcium supplementation could prevent bone loss in postmenopausal women or more favourable outcomes could be obtained via the consumption of dairy products fortified with calcium and vitamin $\mathrm{D}_{3}$. For this purpose changes in bone mineral density (BMD) at different skeletal sites, assessed by dual-energy X-ray absorptiometry, as well as in quantitative ultrasound (QUS) parameters of the calcaneus over 12 months were estimated. A population of 101 postmenopausal women (55-65 years old) was randomized into a dairy group (DG: $n$ 39), receiving approximately $1200 \mathrm{mg}$ calcium/d and $7.5 \mu \mathrm{g}$ vitamin $\mathrm{D}_{3} / \mathrm{d}$ through fortified dairy products; a calcium-supplemented group (CaG: $n$ 26) provided with a calcium supplement of $600 \mathrm{mg} / \mathrm{d}$; and a control group (CG: $n$ 36). Over the intervention period the DG was found to have more favourable changes in pelvis $(P=0.040)$, total spine $(P<0.001)$ and total body BMD $(P<0 \cdot 001)$ than the other groups. A significant increase was also observed for DG in lumbar spine BMD $(2.0 \%$; $95 \%$ CI $0.5,3.5)$ although it did not differentiate significantly compared to the other groups. No significant differences were observed with respect to the changes in QUS parameters. The current study revealed that recommended intakes of vitamin $\mathrm{D}_{3}$ and calcium via fortified dairy products for 12 months can induce favourable changes in pelvis, total spine and total body BMD in postmenopausal women but not in QUS parameters. No such favourable changes were observed via supplementation of calcium alone.
\end{abstract}

Bone mineral density: Calcium and vitamin D: Intervention: Quantitative ultrasound

Osteoporosis and the subsequent risk of bone fracture occur most commonly among middle-aged and older postmenopausal women. These disorders account for a significant burden of morbidity and mortality worldwide and have become a major public health problem (Hodgson et al. 2003). Several dietary and pharmaceutical intervention studies have been conducted, aiming at minimizing bone loss in postmenopausal women. The results of these studies have indicated that treatment can induce small to moderate retardation of the age-related bone loss at susceptible-to-fracture skeletal sites (i.e. lumbar spine, femoral neck, total hip etc.) (Reid et al. 1995; Riggs et al. 1998; Storm et al. 1998; Heaney et al. 1999; Rosenthall et al. 1999; Hunter et al. 2000; Frost et al. 2001a; Chapuy et al. 2002; Lau et al. 2002; Chee et al. 2003; McClung et al. 2004; Meier et al. 2004; Engelke et al. 2006; Jackson et al. 2006). However, the abovereported changes do not always lead to a significant decrease in fracture risk, as recently indicated by the Women's Health Initiative study (Jackson et al. 2006).

The effectiveness of these interventions is usually assessed by changes in bone mineral density (BMD; Prince et al. 1995; Dawson-Hughes et al. 1997; Baeksgaard et al. 1998;
Riggs et al. 1998; Storm et al. 1998; Heaney et al. 1999; Lau et al. 2002; Chee et al. 2003; McClung et al. 2004; Meier et al. 2004). Measurement of BMD with dual-energy X-ray absorptiometry (DXA) is considered the 'gold standard' technique, which is widely used in clinical practice for fracture risk discrimination and/or prediction, for the diagnosis of osteoporosis and for monitoring skeletal status changes, mainly due to its relatively high reproducibility and longitudinal sensitivity (Gluer, 1999; Fogelman \& Blake, 2000). However, over the last decade quantitative ultrasound (QUS), most commonly of the calcaneus, has been alternatively used for the assessment of all the aforementioned clinical aspects (Hans et al. 1996; Bauer et al. 1997; Gluer, 1997; Frost et al. 2001b; Pinheiro et al. 2003). This could be attributed to certain additional benefits of QUS, including low cost, simplicity of use, potential portability and absence of ionizing radiation risk (Njeh, 1999).

However, very few dietary intervention studies so far have assessed response of skeletal status to treatment via the exclusive monitoring of QUS parameters. These studies have shown no significant changes during 12 months of intervention (Krieg et al. 1999; Palacios et al. 2005), while only one showed

\footnotetext{
Abbreviations: BMD, bone mineral density; BUA, broadband ultrasound attenuation; CaG, calcium-supplemented group; CG, control group; DG, dairy group; DXA, dual-energy X-ray absorptiometry; QUS, quantitative ultrasound; SOS, speed of sound.

*Corresponding author: Dr Yannis Manios, fax +30 210 9514759, email manios@hua.gr
} 
significant changes over 24 and 36 months, respectively (Krieg et al. 1999). These observations could probably be attributed to the fact that, either the dietary intervention scheme followed was not effective in delivering desirable skeletal status changes or that QUS is not sensitive enough to detect any possible changes delivered over a 12-month period.

The very few dietary intervention studies available using a combination of both DXA and QUS measurements to monitor changes in skeletal status, provide inconsistent results (Hunter et al. 2000; Chapuy et al. 2002; Engelke et al. 2006). These earlier findings highlight the need for further research in the area of prevention via dietary interventions as well as in the area of techniques used to monitor skeletal response to treatment, so as to improve accuracy in assessing changes in bone properties (i.e. density, architecture, turnover and mineralization) over the intervention period. This would increase our knowledge and understanding on the changes that could be obtained by the implementation of dietary intervention schemes, which consequently could be used to improve the existing preventive measures and guidelines for minimizing bone loss and fracture risk.

More specifically, in the case of Greece, low calcium intake ranging from 500 to $700 \mathrm{mg} / \mathrm{d}$ has been reported for postmenopausal women (Babaroutsi et al. 2005), while no recent data are available on serum vitamin D status for this population. The general belief in Greece, but also in other Mediterranean countries, is that due to sunny weather conditions vitamin D deficiency should not be a health issue for postmenopausal women. This and the notion that the population is following a more or less balanced diet not requiring any kind of dietary counselling intervention, has led health professionals to minimize their preventive strategy in prescribing calcium supplementation.

The aim of the current study was to examine whether the use of calcium supplementation could prevent bone loss in healthy free-living postmenopausal women or more favourable outcomes could be obtained using a holistic approach combining dietary intervention and consumption of dairy products fortified with calcium and vitamin $\mathrm{D}_{3}$. The effectiveness of the aforementioned two treatment arms was tested via the changes induced over the 12-month intervention period in BMD at different skeletal sites as well as in the QUS parameters of the calcaneus.

\section{Materials and methods}

\section{Sampling}

First screening. The study was initiated in July 2004 with the approval of the Ethical Committee of Harokopio University of Athens. During July 2004 volunteers were invited to participate by informational brochures and posters distributed in public buildings and community centres in three municipalities within the wider district of Athens, namely Nea Smyrni, Kallithea and Neo Iraklio. Through this initial screening, conducted in the premises of the aforementioned settings and with the co-operation of the local authorities, a sample of 307 Greek postmenopausal women volunteered to participate. The first screening comprised a short questionnaire primarily focusing on gathering information on the women's medical history, demographic data, dietary, physical activity and smoking habits. Furthermore, bone status of all volunteers was assessed by calcaneal QUS measurement, carried out using the SAHARA Clinical Bone Sonometer (Hologic Inc., Waltham, MA, USA). Through this initial screening those women diagnosed having a T-score lower than -2.5 , taking medications (i.e. thiazide diuretics, glucocorticoids) and/or dietary supplements (calcium, magnesium, phosphate or vitamin D) that affect bone metabolism, having any kind of degenerative chronic disease (i.e. diabetes, nephrolithiasis, heart disease, cancer, hyper- and hypothyroidism, hyperparathyroidism, impaired renal and liver function), smoking and being at menopause for less than 1 year were excluded from the second screening of the study.

Second screening. After the initial screening 134 women (age 55-65 years) satisfying the inclusion criteria were identified and were invited to participate at the second screening of the study. During the second screening all volunteers underwent a DXA (Lunar DPX-MD, Madison, WI, USA) measurement, as well as haematological and biochemical examinations, comprising haematological profile, erythrocyte sedimentation rate and serum calcium, phosphorus, glutamic-oxaloacetic and glutamic pyruvic transaminases, alkaline phosphatase and creatinine levels. Those women found to be osteoporotic, according to the data provided by the DXA examination, or having abnormal values on the aforementioned blood indices, were excluded from the study. This second screening yielded 112 eligible women who prior to their entry to the study signed detailed consent forms of participation and proceeded in the intervention study. The intervention component of the study was initiated in October 2004.

Study groups. These 112 eligible women were randomly assigned to three groups, a dairy group (DG), a calcium-supplemented group $(\mathrm{CaG})$ and a control group $(\mathrm{CG})$, using a table of random digits. The DG consisted of forty-two women, who were advised to consume three portions of low-fat dairy products (milk and yogurt) fortified with calcium and vitamin $\mathrm{D}_{3}$ on a daily basis. To ensure compliance with the intervention scheme, 'Health and Nutrition Education' sessions were held biweekly within the settings of the university and the required quantities of fortified dairy products for the next two weeks were provided at the end of the sessions. These products were enriched with calcium, providing a total of $400 \mathrm{mg}$ calcium/portion (one portion is equal to $250 \mathrm{ml}$ milk and to $200 \mathrm{~g}$ yogurt). The extra calcium source was milk protein concentrate, a natural source of milk calcium. Regarding vitamin $\mathrm{D}$ each portion provided $2.5 \mu \mathrm{g}$ vitamin $\mathrm{D}_{3}$. The aim of the sessions delivered to the DG was to increase awareness of the subjects on health issues, primarily related to osteoporosis, but also to motivate them to change certain lifestyle and dietary habits in order to improve their health status. The first sessions primarily focused on educating the subjects on the pathophysiology of osteoporosis as well as the risk factors (health-related behaviours) related to its development. Gradually the sessions became more interactive and emphasis was given in guiding and assisting the subjects in changing their dietary habits. In order to avoid excess caloric intake subjects in the DG were advised to substitute other dairy products in their diet with those provided, while the new dietary scheme that they were advised to follow was low in fat but efficient in providing the recommended daily intake of calcium and vitamin D (about $1200 \mathrm{mg}$ calcium/d and $7.5 \mu \mathrm{g}$ vitamin $\mathrm{D} / \mathrm{d}$ ). 
The $\mathrm{CaG}$ consisted of thirty women who received an extra amount of $600 \mathrm{mg}$ supplementary calcium (87\% of calcium lactate gluconate and $13 \%$ of calcium carbonate) per day in the form of water-soluble tablets. This extra quantity was added to the estimated dietary calcium intake aiming to a minimum of $1200 \mathrm{mg} / \mathrm{d}$. Supplements were provided to the subjects via home delivery on a monthly basis. Adherence to the supplement use was established by checking for remaining tablets in the returned packages from the previous home delivery but also via weekly phone calls. Finally, the CG consisted of forty women, to whom no intervention was delivered as they continued with their usual diet. The sample sizes in the three groups were adequate since we achieved statistical power greater than $90 \%$ for standardized differences for the main outcomes of the present study (i.e. BMD and QUS parameters) between groups greater than 2.5 (SE1.4) at probability of Type I error $<0.05$. Randomization ended up giving unequal size study groups since we over-recruited subjects in the DG and the CG, due to our intention to counter anticipated higher rates of dropout from these two groups.

\section{Assessment of the effectiveness of the intervention}

During the intervention period the subjects from all study groups were invited to go through certain examinations primarily focusing on the assessment of behavioural and clinical indices. The data obtained from the second screening of the study were used as baseline data. A mid-term examination took place in March 2005 after 5 months of intervention, while the final examination was conducted after 12 months of intervention at September/October 2005. At baseline, mid-term and the final examination the following measurements were obtained.

\section{Anthropometrical measures}

Anthropometry was carried out during the initial screening, as well as at baseline and follow-up re-examinations. In all the aforementioned time-points body weight and standing height were measured in light clothing and with no shoes using a digital scale (Seca) with an accuracy of $\pm 100 \mathrm{~g}$ and a commercial stadiometer (Leicester Height Measure) to the nearest $0.5 \mathrm{~cm}$, respectively. BMI was calculated as weight $(\mathrm{kg})$ divided by height squared $\left(\mathrm{m}^{2}\right)$.

\section{Nutritional assessment}

At baseline, mid-term and final examinations the $24 \mathrm{~h}$ recall technique was used to collect dietary intake information for a total of $3 \mathrm{~d}$, two weekdays and one weekend day, most preferably Sunday. All interviewers were rigorously trained to minimize interviewer effects. Respondents were asked to recall the type and amount of any food and beverage consumed during the previous day in a chronological order, i.e. from the time they woke up in the morning to the same time the following day. To improve the accuracy of food descriptions and portion sizes, standard household measures (cups, tablespoons, etc.) and picture food models (National Dairy Council, Rosemont, IL, USA) were used during interviews to define amounts when appropriate. Food intake data were analysed using the Nutritionist V diet analysis software (First Databank, San Bruno, CA,
USA), which was extensively amended to include Food Composition Tables for Greek foods and recipes (University of Crete, 1991; Trichopoulou, 2004) and chemically analysed commercial food items widely consumed in Greece.

The distribution of usual intakes was estimated by using the National Research Council method (National Research Council, 1986; Institute of Medicine Food \& Nutrition Board, 2001), which attempts to remove the effects of day-to-day (within-subject) and the subject-by-subject (between subjects) variability in dietary intakes. More specifically, the equation used for the calculation of adjusted (usual) intake was the following:

$$
\begin{aligned}
\text { Adjusted intake } & =[(\text { Subject's mean }- \text { Group mean }) \\
& \left.\times \mathrm{SD}_{\text {between-person }} / \mathrm{SD}_{\text {observed }}\right]+ \text { group mean },
\end{aligned}
$$

where 'subject's mean' is the mean dietary intake of each subject as obtained by the $3 \mathrm{~d}$ dietary recalls; 'group mean' is the mean dietary intake of the studied population; $\mathrm{SD}_{\text {between-person }}$ is the standard deviation of the distribution of usual intakes, corrected for the effects of the within-subject variability; and $\mathrm{SD}_{\text {observed }}$ is the standard deviation of the distribution of the reported intakes.

\section{Physical activity assessment}

Assessment of physical activity was made by a $3 \mathrm{~d}$ activity interview questionnaire. Respondents reported the time spent on various physical activities during two consecutive weekdays and one weekend day. The questionnaire classified all work, sport and leisure activities into four categories, on the basis of their average intensity relative to the impact on the cardiovascular system (low to high), and also by subgrouping activities according to their impact on bone mass (low to high) (Groothausen et al. 1997). The aim of the questionnaire was to determine the frequency and duration (hours per session) subjects devoted weekly in these physical activity categories. The total amount of time devoted weekly on activity categories having intensity higher than four metabolic equivalents was defined as time spent on moderate-to-vigorous physical activities. Similarly, the time devoted weekly in activity categories having intensity lower than two metabolic equivalents was defined as time spent on sedentary activities. As the commonest sedentary activity recorded was television watching the time devoted on this activity alone was examined separately as an indication of sedentarism.

\section{Bone mineral density and total body composition measurements}

BMD $\left(\mathrm{g} / \mathrm{cm}^{2}\right)$ of the lumbar spine (L2-L4) and total body composition (i.e. total and segmental BMD, lean and fat mass) were measured at baseline and at the final examination by DXA with the analysis software version 4.6. A daily quality assurance check was performed using a calibration standard of known composition, provided by the manufacturer. Before the beginning of the study the $\mathrm{CV}$ was estimated with a total body phantom and total BMD measurements were $0.7 \%$, while those for regional sites ranged from 1 to $2 \%$. The scans were performed in the morning by an experienced technician. 


\section{Quantitative ultrasound measurements}

Calcaneal QUS measurements were carried out by the SAHARA Clinical Bone Sonometer (Hologic). For the Sahara device, sound transducers are mounted coaxially on a motorized calliper that enables direct contact with the heel through elastomer pads and an ultrasonic coupling gel. One transducer acts as a transmitter and the other as a receiver. The position of the foot, ankle and leg were fixed by a positioning aid that extended from the foot to midshin, in order to avoid possible rotations of the heel that could interfere with the measurements. Broadband ultrasound attenuation (BUA, dB/MHz) and speed of sound ( $\mathrm{SOS}, \mathrm{m} / \mathrm{s}$ ) were measured at a fixed region in the midcalcaneus. BUA and SOS were then combined into a single parameter, the quantitative ultrasound index $(\%)$ or stiffness index. An estimate of heel BMD $\left(\mathrm{g} / \mathrm{cm}^{2}\right)$ was also derived. Measurements were obtained for both the left and right heel in all women and the means of the two sides were used in subsequent analyses. Quality control checking was performed daily, by scanning phantoms provided by the manufacturer prior to testing the subjects. The short-term reproducibility of the measurements was assessed in vivo by triplicate scans with repositioning in thirty unselected subjects. CV for BUA, SOS, quantitative ultrasound index and estimate of heel BMD were 2.6, 0.4, 2.7 and $2.9 \%$, respectively. More details on QUS measurements, calculations and standardization procedures are presented elsewhere (Magkos et al. 2005).

\section{Statistical analysis}

All data are reported as mean and their standard errors and as mean percentage change (with $95 \%$ CI) over baseline. The Kolmogorov-Smirnov test was used to determine normality of distribution of the examined variables. Differences in baseline characteristics among the three groups of women were evaluated by using one-way ANOVA. Repeated measures ANOVA was used to evaluate the significance of the differences between groups at baseline and at 12 months followup (treatment effect), the significance of the changes observed within each group (time effect) and the effect of the treatment $\times$ time interaction. The between-group factor was the study groups (i.e. $\mathrm{DG} v$. $\mathrm{CG} v$. $\mathrm{CaG}$ ); the within-group factor was the time-point of measurement (i.e. baseline and 12 months of intervention). The inflation in Type I error due to multiple post hoc comparisons between groups was corrected using the Bonferroni rule. All $P$ values reported are two-tailed. Statistical analysis was conducted with SPSS version 11.0 (SPSS Inc., Chicago, IL, USA). The level of statistical significance was set at $P \leq 0 \cdot 05$.

\section{Results}

Eleven of the 112 women initially assigned to participate in the study could not be re-examined at follow-up, providing a total of 101 women with full data from both examinations. Of these eleven subjects, three from the DG dropped out due to personal reasons, whereas four subjects from the $\mathrm{CG}$ either could not be tracked down or were not available to participate at follow-up examinations. Furthermore, four women from the $\mathrm{CaG}$ withdrew, due to complaints of side-effects, such as bloating, constipation and intestinal discomfort apparently related to the supplement used. Consequently, the number of subjects in each group with full baseline and follow-up data was thirty-nine for the DG, thirty-six for the $\mathrm{CG}$ and twenty-six for the $\mathrm{CaG}$. The mean age of these women was $60 \cdot 5$ (SE 5.1) years (age range 55-65 years) and the average time since their menopause was $9 \cdot 5$ (SE 5.6) years.

The baseline characteristics of the 101 study participants with full data in both baseline and follow-up examinations are summarized in Table 1. No differences were observed between the three groups examined, thus indicating homogeneity in baseline demographic, anthropometrical and body composition characteristics. Regarding compliance to the dairy intervention scheme this was assessed via information obtained at the biweekly sessions, combined with data obtained from the nutritional assessments conducted at baseline, 5 and 12 months of intervention. These data showed that the compliance to the intervention scheme was reaching a rate of $93 \%$ (range $89-100 \%$ ). Similarly, adherence of the subjects in the $\mathrm{CaG}$ to the intervention scheme was assessed by checking for remaining calcium tablets in the returned packages but also via weekly phone calls. This information showed that the compliance rate was approximately $95 \%$ (range $91-100 \%$ ).

Tables 2 and 3 summarize the comparisons among groups with respect to the changes observed from baseline to the 12-month follow-up in certain behaviours related to bone metabolism (i.e. diet and physical activity). Precisely, the DG showed a higher increase in the consumption of dairy products $(P=0.004)$ and in the intake of protein $(P=0.001)$,

Table 1. Baseline descriptive characteristics by group

\begin{tabular}{|c|c|c|c|c|c|c|c|}
\hline & \multicolumn{2}{|c|}{$\begin{array}{l}\text { Dairy group } \\
\quad(n 39)\end{array}$} & \multicolumn{2}{|c|}{$\begin{array}{l}\text { Control group } \\
\qquad(n 36)\end{array}$} & \multicolumn{2}{|c|}{$\begin{array}{l}\text { Calcium- } \\
\text { supplemented } \\
\text { group ( } n 26)\end{array}$} & \multirow[b]{2}{*}{$P$ value } \\
\hline & Mean & SE & Mean & SE & Mean & SE & \\
\hline Age (years) & $60 \cdot 5$ & 0.71 & $61 \cdot 4$ & 0.85 & $62 \cdot 4$ & 1.87 & 0.087 \\
\hline Years since menopause & $9 \cdot 25$ & 0.95 & $10 \cdot 4$ & $1 \cdot 11$ & 11.4 & $2 \cdot 26$ & 0.210 \\
\hline Weight (kg) & $71 \cdot 2$ & 1.50 & 74.9 & 2.02 & $72 \cdot 8$ & $2 \cdot 36$ & 0.319 \\
\hline Height (cm) & $158 \cdot 9$ & 1.07 & $156 \cdot 9$ & 0.98 & $155 \cdot 1$ & 1.55 & 0.130 \\
\hline $\mathrm{BMI}\left(\mathrm{kg} / \mathrm{m}^{2}\right)$ & $28 \cdot 3$ & 0.64 & 30.5 & 0.88 & 30.4 & $1 \cdot 19$ & 0.087 \\
\hline Fat body mass (kg) & $31 \cdot 2$ & 1.08 & $33 \cdot 3$ & $2 \cdot 24$ & $31 \cdot 8$ & 1.67 & 0.401 \\
\hline Lean body mass (kg) & $37 \cdot 7$ & 0.60 & $38 \cdot 9$ & 0.75 & $38 \cdot 2$ & 1.04 & 0.466 \\
\hline
\end{tabular}

* Derived by one-way ANOVA. 
Table 2. Changes in the consumption of dairy products and the intake of energy, macro- and micronutrients related to bone metabolism*

\begin{tabular}{|c|c|c|c|c|c|}
\hline & \multicolumn{2}{|c|}{ Baseline } & \multicolumn{2}{|c|}{ After 12 months } & \multirow[b]{2}{*}{$P$ value $\dagger$} \\
\hline & Mean & SE & Mean & SE & \\
\hline Dairy consumption (portions/d) & & & & & 0.004 \\
\hline Control group & 1.8 & 0.2 & $1.9^{\mathrm{a}}$ & 0.2 & \\
\hline Calcium-supplemented group & 1.6 & 0.3 & $2 \cdot 1^{\mathrm{b}}$ & 0.4 & \\
\hline Dairy group & 1.8 & 0.2 & $3 \cdot 3^{a, b}$ & 0.2 & \\
\hline$P$ value $\neq$ & 0.807 & & $<0.001$ & & \\
\hline Energy intake (kJ/d) & & & & & 0.362 \\
\hline Control group & $7159 \cdot 9$ & $221 \cdot 7$ & $6558 \cdot 8$ & 223.5 & \\
\hline Calcium-supplemented group & $6715 \cdot 6$ & 374.1 & $6440 \cdot 9$ & 377.1 & \\
\hline Dairy group & $6815 \cdot 8$ & $215 \cdot 9$ & $6672 \cdot 8$ & $217 \cdot 7$ & \\
\hline$P$ value $\neq$ & 0.437 & & 0.852 & & \\
\hline Protein intake $(\mathrm{g} / \mathrm{d})$ & & & & & 0.001 \\
\hline Control group & $55 \cdot 3$ & 2.5 & $54.0^{\mathrm{a}}$ & $2 \cdot 4$ & \\
\hline Calcium-supplemented group & $57 \cdot 6$ & $4 \cdot 2$ & $50 \cdot 5^{\mathrm{b}}$ & $4 \cdot 1$ & \\
\hline Dairy group & $51 \cdot 8$ & $2 \cdot 4$ & $64 \cdot 1^{a, b}$ & $2 \cdot 3$ & \\
\hline$P$ value $\ddagger$ & 0.413 & & 0.002 & & \\
\hline Calcium intake $(\mathrm{mg} / \mathrm{d})$ & & & & & $<0.001$ \\
\hline Control group & $712 \cdot 7$ & $43 \cdot 3$ & $723 \cdot 7^{\mathrm{a}, \mathrm{c}}$ & $55 \cdot 1$ & \\
\hline Calcium-supplemented group & 638.6 & $157 \cdot 1$ & $1147 \cdot 4^{\mathrm{c}}$ & $94 \cdot 1$ & \\
\hline Dairy group & 687.2 & 41.0 & $1135 \cdot 6^{\mathrm{a}}$ & $52 \cdot 2$ & \\
\hline$P$ value $\neq$ & 0.668 & & $<0.001$ & & \\
\hline Phosphorus intake (mg/d) & & & & & 0.087 \\
\hline Control group & $975 \cdot 3$ & $49 \cdot 8$ & $1062 \cdot 3^{a}$ & $59 \cdot 8$ & \\
\hline Calcium-supplemented group & 844.8 & $84 \cdot 1$ & $958.5^{\mathrm{b}}$ & $100 \cdot 8$ & \\
\hline Dairy group & $1005 \cdot 2$ & 48.5 & $1299 \cdot 3^{\mathrm{a}, \mathrm{b}}$ & $58 \cdot 2$ & \\
\hline$P$ value $\neq$ & 0.258 & & 0.003 & & \\
\hline Magnesium intake $(\mathrm{mg} / \mathrm{d})$ & & & & & $<0.001$ \\
\hline Control group & $204 \cdot 2$ & $8 \cdot 7$ & $208 \cdot 9^{a}$ & $13 \cdot 9$ & \\
\hline Calcium-supplemented group & $222 \cdot 6$ & $19 \cdot 9$ & $191.9^{b}$ & $23 \cdot 3$ & \\
\hline Dairy group & $196 \cdot 5$ & $8 \cdot 1$ & $289 \cdot 2^{a, b}$ & $12 \cdot 9$ & \\
\hline$P$ value $\neq$ & 0.519 & & $<0.001$ & & \\
\hline Vitamin D $(\mu \mathrm{g} / \mathrm{d})$ & & & & & $<0.001$ \\
\hline Control group & 0.59 & 0.13 & $1.00^{\mathrm{a}}$ & 0.29 & \\
\hline Calcium-supplemented group & 0.52 & 0.23 & $0.44^{\mathrm{b}}$ & 0.52 & \\
\hline Dairy group & 0.67 & $0 \cdot 12$ & $5 \cdot 21^{a, b}$ & 0.27 & \\
\hline$P$ value $\ddagger$ & 0.472 & & $<0.001$ & & \\
\hline
\end{tabular}

a,b,c Pairwise differences between groups at 12 months derived by post hoc multiple comparisons using Bonferroni rule to correct the inflation in Type I error: ${ }^{a} P<0.05$ dairy $v$. control group; ${ }^{\text {b }} P<0.05$ dairy $v$. calcium-supplemented group; ${ }^{c} P<0.05$ calcium-supplemented $v$. control group.

${ }^{*}$ For details of procedures, see pp. 1141-1143.

$\dagger$ Treatment $\times$ time interaction effect.

$\ddagger$ Between-groups comparisons at baseline and 12 months (treatment effect).

magnesium $(P<0 \cdot 001)$ and vitamin $\mathrm{D}(P<0 \cdot 001)$ compared to the changes observed in the other two groups. Regarding calcium intake the increase observed in subjects of both the DG and the $\mathrm{CaG}$ was higher compared to the change in the $\mathrm{CG}$ $(P<0 \cdot 001)$. However, no differences were observed among the three study groups with respect to the changes observed in their average energy intake over the 12-month intervention period. Furthermore, no differences were observed among groups with respect to the changes in BMI and time devoted to moderate-to-vigorous physical activities over the intervention period, although subjects in the DG tended to have a lower increase in time devoted to television watching than subjects in the $\mathrm{CaG}$ and the $\mathrm{CG}(P=0 \cdot 061)$.

According to the data presented in Table 4, at the end of the intervention period the DG was found to have more favourable changes in pelvis $(P=0.040)$, total spine $(P<0.001)$ and total body $\mathrm{BMD}(P<0 \cdot 001)$, compared to the $\mathrm{CaG}$ and the $\mathrm{CG}$, respectively. Regarding between-group differences at the 12 month follow-up, the DG were found to have higher levels of pelvis $(P=0.026)$, total spine $(P=0.019)$ and total body
( $P=0.014)$ BMD, compared to the other two groups. Within groups, lumbar spine $(2.0 \% ; 95 \%$ CI $0.5,3.5)$, pelvis $(0.9 \% ; 95 \%$ CI $0.1,2.3)$, total spine $(4.7 \% ; 95 \%$ CI 2.5 , $7 \cdot 2)$ and total body $(1.5 \% ; 95 \%$ CI $0.9,2.2)$ BMD increased significantly over the 12-month intervention only in the DG. On the contrary, significant decreases were observed for the $\mathrm{CG}$ in total spine $(-4.0 \% ; 95 \% \mathrm{CI}-6.5,-1.1)$ and total body $(-0.7 \%$; $95 \%$ CI $-1.4,-0.1)$ BMD, while arms BMD decreased significantly in both DG $(-2.4 \%$; $95 \%$ CI $-4 \cdot 0,-0.6)$ and CG $(-4 \cdot 1 ; 95 \%$ CI $-6 \cdot 2,-1 \cdot 8)$. No other significant changes within groups were observed.

The 12-month changes in QUS parameters are summarized in Table 5. No significant differences between groups and no significant changes within groups were observed.

\section{Discussion}

Over the 12-month intervention period certain favourable dietary changes have been observed for the DG and to a lesser extent for the $\mathrm{CaG}$ (Table 2). More specifically both DG 
Table 3. Changes in BMI and time devoted to moderate-to-vigorous physical activities and television watching*

\begin{tabular}{|c|c|c|c|c|c|}
\hline & \multicolumn{2}{|c|}{ Baseline } & \multicolumn{2}{|c|}{ After 12 months } & \multirow[b]{2}{*}{$P$ value $\dagger$} \\
\hline & Mean & SE & Mean & SE & \\
\hline BMI $\left(\mathrm{kg} / \mathrm{m}^{2}\right)$ & & & & & 0.255 \\
\hline Control group & 30.5 & 0.88 & 30.4 & 0.88 & \\
\hline Calcium-supplemented group & $30 \cdot 4$ & $1 \cdot 19$ & $30 \cdot 7$ & 1.49 & \\
\hline Dairy group & $28 \cdot 3$ & 0.64 & 28.9 & 0.86 & \\
\hline$P$ value $\ddagger$ & 0.087 & & 0.388 & & \\
\hline Moderate-to-vigorous physical activity ( $\mathrm{min} /$ week) & & & & & 0.922 \\
\hline Control group & $109 \cdot 4$ & $25 \cdot 8$ & 87.8 & 21.9 & \\
\hline Calcium-supplemented group & 124.5 & $48 \cdot 4$ & $112 \cdot 0$ & $41 \cdot 0$ & \\
\hline Dairy group & $136 \cdot 1$ & 24.5 & 128.4 & $20 \cdot 8$ & \\
\hline$P$ value $\ddagger$ & 0.648 & & 0.313 & & \\
\hline Television watching $(\mathrm{h} / \mathrm{d})$ & & & & & 0.061 \\
\hline Control group & $2 \cdot 29$ & 0.24 & 4.33 & 0.39 & \\
\hline Calcium-supplemented group & $1 \cdot 80$ & 0.41 & 3.74 & 0.68 & \\
\hline Dairy group & $2 \cdot 39$ & 0.23 & 3.05 & 0.38 & \\
\hline$P$ value $\ddagger$ & 0.458 & & 0.068 & & \\
\hline
\end{tabular}

${ }^{*}$ For details of procedures, see pp. 1141-1143.

$\dagger$ Treatment $\times$ time interaction effect.

$\ddagger$ Between-groups comparisons at baseline and 12 months (treatment effect).

Table 4. Changes in bone mineral density (BMD) at various skeletal sites*

\begin{tabular}{|c|c|c|c|c|c|c|c|}
\hline & \multicolumn{2}{|c|}{ Baseline } & \multicolumn{2}{|c|}{ After 12 months } & \multicolumn{2}{|c|}{$\begin{array}{l}\text { 12-month change } \\
\text { (\% over baseline) }\end{array}$} & \multirow[b]{2}{*}{$P$ value } \\
\hline & Mean & SE & Mean & SE & Mean & $95 \% \mathrm{Cl}$ & \\
\hline Lumbar spine (L2-L4) BMD (g/cm²) & & & & & & & 0.346 \\
\hline Control group & 1.052 & 0.033 & 1.043 & 0.030 & -0.8 & $-3 \cdot 1,3 \cdot 3$ & \\
\hline Calcium-supplemented group & 1.089 & 0.053 & 1.092 & 0.048 & 0.3 & $-3 \cdot 2,4 \cdot 6$ & \\
\hline Dairy group & 1.091 & 0.028 & $1 \cdot 113$ & 0.026 & $2 \cdot 0$ & $0.5,3.5$ & \\
\hline$P$ value $\neq$ & 0.643 & & 0.222 & & & & \\
\hline Pelvis BMD $\left(\mathrm{g} / \mathrm{cm}^{2}\right)$ & & & & & & & 0.040 \\
\hline Control group & 1.071 & 0.016 & $1.068^{a}$ & 0.016 & -0.3 & $-1 \cdot 6,1 \cdot 1$ & \\
\hline Calcium-supplemented group & 1.032 & 0.025 & $1.037^{\mathrm{b}}$ & 0.025 & 0.5 & $-1 \cdot 5,2 \cdot 4$ & \\
\hline Dairy group & $1 \cdot 100$ & 0.014 & $1 \cdot 110^{a, b}$ & 0.014 & 0.9 & $0 \cdot 1,2 \cdot 3$ & \\
\hline$P$ value $\neq$ & 0.061 & & 0.026 & & & & \\
\hline Total spine BMD (g/cm²) & & & & & & & $<0.001$ \\
\hline Control group & $1 \cdot 134$ & 0.025 & $1 \cdot 089^{a}$ & 0.027 & $-4 \cdot 0$ & $-6 \cdot 6,-1 \cdot 1$ & \\
\hline Calcium-supplemented group & 1.055 & 0.039 & $1.063^{b}$ & 0.041 & 0.8 & $-2 \cdot 5,4.5$ & \\
\hline Dairy group & $1 \cdot 122$ & 0.022 & $1 \cdot 175^{a, b}$ & 0.023 & $4 \cdot 7$ & $2 \cdot 5,7 \cdot 2$ & \\
\hline$P$ value $\neq$ & 0.219 & & 0.019 & & & & \\
\hline Arms BMD $\left(\mathrm{g} / \mathrm{cm}^{2}\right)$ & & & & & & & 0.126 \\
\hline Control group & 0.844 & 0.015 & 0.809 & 0.015 & $-4 \cdot 1$ & $-6 \cdot 2,-1 \cdot 8$ & \\
\hline Calcium-supplemented group & 0.802 & 0.023 & 0.798 & 0.023 & -0.5 & $-2 \cdot 4,1 \cdot 2$ & \\
\hline Dairy group & 0.827 & 0.013 & 0.807 & 0.013 & $-2 \cdot 4$ & $-4.0,-0.6$ & \\
\hline$P$ value $\ddagger$ & 0.310 & & 0.922 & & & & \\
\hline Legs BMD $\left(\mathrm{g} / \mathrm{cm}^{2}\right)$ & & & & & & & 0.150 \\
\hline Control group & $1 \cdot 130$ & 0.015 & $1 \cdot 134$ & 0.015 & 0.3 & $-0.5,1.3$ & \\
\hline Calcium-supplemented group & $1 \cdot 121$ & 0.025 & $1 \cdot 127$ & 0.023 & 0.5 & $-0.9,2 \cdot 0$ & \\
\hline Dairy group & $1 \cdot 154$ & 0.014 & $1 \cdot 147$ & 0.013 & -0.6 & $-1 \cdot 3,0.2$ & \\
\hline$P$ value $\neq$ & 0.373 & & 0.685 & & & & \\
\hline Total body BMD (g/cm²) & & & & & & & $<0.001$ \\
\hline Control group & $1 \cdot 120$ & 0.014 & $1 \cdot 112^{a}$ & 0.013 & -0.7 & $-1.4,-0.1$ & \\
\hline Calcium-supplemented group & $1 \cdot 077$ & 0.022 & $1.083^{b}$ & 0.021 & 0.6 & $-0.4,1.6$ & \\
\hline Dairy group & $1 \cdot 133$ & 0.012 & $1 \cdot 150^{a, b}$ & 0.012 & 1.5 & $0.9,2 \cdot 2$ & \\
\hline$P$ value $\neq$ & 0.089 & & 0.014 & & & & \\
\hline
\end{tabular}


Table 5. Changes in calcaneal quantitative ultrasound (QUS) parameters*

\begin{tabular}{|c|c|c|c|c|c|c|c|}
\hline & \multicolumn{2}{|c|}{ Baseline } & \multicolumn{2}{|c|}{ After 12 months } & \multicolumn{2}{|c|}{$\begin{array}{l}\text { 12-month change } \\
\text { (\% over baseline) }\end{array}$} & \multirow[b]{2}{*}{$P$ value $\dagger$} \\
\hline & Mean & SE & Mean & SE & Mean & $95 \% \mathrm{Cl}$ & \\
\hline $\mathrm{SOS}(\mathrm{m} / \mathrm{s})$ & & & & & & & 0.433 \\
\hline Control group & $1530 \cdot 4$ & 4.6 & $1530 \cdot 3$ & $5 \cdot 3$ & 0.0 & $-0.2,0.2$ & \\
\hline Calcium-supplemented group & $1525 \cdot 8$ & $8 \cdot 3$ & $1526 \cdot 9$ & 9.5 & 0.1 & $-0.1,0.3$ & \\
\hline Dairy group & $1529 \cdot 9$ & $4 \cdot 6$ & 1534.5 & $5 \cdot 3$ & 0.3 & $-0.2,0.7$ & \\
\hline$P$ value $\ddagger$ & 0.886 & & 0.747 & & & & \\
\hline $\operatorname{BMD}\left(\mathrm{g} / \mathrm{cm}^{2}\right)$ & & & & & & & 0.707 \\
\hline Control group & 0.448 & 0.020 & 0.449 & 0.021 & 0.2 & $-1 \cdot 6,3 \cdot 1$ & \\
\hline Calcium-supplemented group & 0.438 & 0.034 & 0.440 & 0.036 & 0.5 & $-1 \cdot 3,4 \cdot 6$ & \\
\hline Dairy group & 0.458 & 0.019 & 0.470 & 0.021 & $2 \cdot 6$ & $-3 \cdot 0,9 \cdot 3$ & \\
\hline$P$ value $\ddagger$ & 0.859 & & 0.683 & & & & \\
\hline $\mathrm{BUA}(\mathrm{dB} / \mathrm{MHz})$ & & & & & & & 0.879 \\
\hline Control group & 64.5 & $2 \cdot 8$ & $65 \cdot 1$ & 2.9 & 0.9 & $-2 \cdot 6,6 \cdot 0$ & \\
\hline Calcium-supplemented group & $61 \cdot 6$ & $5 \cdot 1$ & 61.9 & $5 \cdot 3$ & 0.5 & $-1 \cdot 1,3 \cdot 8$ & \\
\hline Dairy group & $64 \cdot 3$ & $2 \cdot 8$ & $65 \cdot 6$ & 2.9 & $2 \cdot 0$ & $-2 \cdot 8,7 \cdot 8$ & \\
\hline$P$ value $\ddagger$ & 0.869 & & 0.827 & & & & \\
\hline QUI/stiffness (\%) & & & & & & & 0.706 \\
\hline Control group & 82.9 & 3.1 & $83 \cdot 1$ & 3.4 & 0.2 & $-1 \cdot 4,2 \cdot 6$ & \\
\hline Calcium-supplemented group & $81 \cdot 4$ & $5 \cdot 3$ & $81 \cdot 6$ & $5 \cdot 7$ & 0.2 & $-1 \cdot 0,3 \cdot 9$ & \\
\hline Dairy group & 84.5 & 3.1 & $86 \cdot 4$ & 3.2 & $2 \cdot 2$ & $-2 \cdot 6,7.9$ & \\
\hline$P$ value $\neq$ & 0.861 & & 0.685 & & & & \\
\hline
\end{tabular}

BMD, bone mineral density; BUA, broadband ultrasound attenuation; QUI, quantitative ultrasound index; SOS, speed of sound.

${ }^{*}$ For details of procedures, see pp. 1141-1143.

$\dagger$ Treatment $\times$ time interaction effect.

$\ddagger$ Between-groups comparisons at baseline and 12 months (treatment effect).

and $\mathrm{CaG}$ increased daily calcium intake to levels exceeding $1000 \mathrm{mg} / \mathrm{d}$, reaching the recommended adequate intake level of $1200 \mathrm{mg} / \mathrm{d}$ (Institute of Medicine Food \& Nutrition Board, 2001). Furthermore, increased intakes of protein, magnesium, phosphorus and vitamin D were observed for the DG compared to the two other groups. The changes in the aforementioned nutrients were mainly delivered by the increased consumption of fortified dairy products provided to the DG subjects. These favourable dietary changes are indicative of the effectiveness of the 'Health and Nutrition Education' component of the programme in increasing the self-efficacy of the population under study to comply with the given dietary instructions. This is also reflected in their total energy intake, which was not differentiated over the intervention period compared to the other two groups. Similar to the present findings, other intervention studies conducted with middle-aged women, including nutrition education as an integral part of their intervention scheme, also reported high adherence to the dietary guidelines provided (Bowen et al. 2002). On the contrary, compliance was considerably lower in intervention programmes not followed by regular nutritional education sessions (Storm et al. 1998).

Regarding physical activity, no differences were observed among groups (Table 3), despite the fact that subjects in the DG were instructed and encouraged to increase their exercise levels. This observation is common in other intervention studies where similar difficulties in motivating middle-aged women already having a sedentary lifestyle to become more active were also confronted (Prince et al. 1995; Wolff et al. 1999). Nonetheless, the lack of significant changes in both physical activity and energy intake levels supports the lack of significant differences among groups with respect to the changes observed in BMI.
Based on the data derived from DXA measurements, the current study showed that ensuring calcium intake of approximately $1200 \mathrm{mg} / \mathrm{d}$ in the $\mathrm{CaG}$ did not manage to induce any favourable bone mass changes in all skeletal sites examined compared to the CG. Similarly to the current study, Prince et al. (1995) observed no BMD changes after providing $1000 \mathrm{mg}$ calcium/d for 1 year to Caucasian women. However, data from other intervention studies conducted with Caucasian cohorts using calcium supplementation as a primary mode of treatment showed that higher doses of $1600 \mathrm{mg} / \mathrm{d}$ were adequate to prevent bone loss from the total body, lumbar spine, femoral neck and greater trochanter (Riggs et al. 1998; Storm et al. 1998).

Contrary to the $\mathrm{CaG}$, significant favourable effects on bone mass (total body, total spine and pelvis BMD) were only apparent for the DG, while no differences were observed for the upper and lower body extremes (Table 4). Similarly bone loss prevention from lumbar spine but no BMD changes at the femoral neck were obtained from a dairy intervention study on Caucasian women with comparable nutrient intake to the current study (Storm et al. 1998). When a similar intervention scheme with fortified dairy products was applied to Asian women (Lau et al. 2002; Chee et al. 2003), comparable favourable bone mass changes in lumbar spine and total body were observed, while additional favourable bone mass changes were also observed for the total hip and femoral neck.

From intervention studies using supplements of comparable doses of calcium but considerably higher doses of vitamin D than those administered in the studies presented earlier, including the present one, limited or no BMD changes were obtained at the examined skeletal sites (Dawson-Hughes et al. 1997; Baeksgaard et al. 1998; Hunter et al. 2000; Chapuy et al. 2002; Meier et al. 2004). From these five studies 
only, three (Dawson-Hughes et al. 1997; Baeksgaard et al. 1998; Meier et al. 2004) reported favourable bone mass changes at the lumbar spine, while none of them reported prevention of bone loss either for total body or at forearm and femoral neck skeletal sites.

Summarizing the findings of the studies presented earlier, supplementation of dairy products fortified with calcium and vitamin $\mathrm{D}_{3}$ consistently showed favourable $\mathrm{BMD}$ changes for total body as well as at several skeletal sites both in Caucasian and Asian cohorts. Still there seems to be a racially different response to treatment, since dairy interventions implemented on Caucasian women, including the present study, consistently reported preservation of bone mass at the lumbar spine but no changes at the lower body extremes. The opposite was observed for Asian women where favourable bone loss retardation was observed in lumbar spine but also bone preservation at the total hip and femoral neck. The different response to treatment between Caucasian and Asian women could be explained by racial differences with respect to spinal and hip bone properties (i.e. density, architecture, turnover and mineralization) (Wu et al. 2003).

The favourable BMD changes observed for subjects in the DG were also followed by increases in QUS parameters of the calcaneus; still the changes observed did not reach a significant level (Table 5). To our knowledge there are no other studies available in the literature examining changes in both BMD and QUS parameters induced by the implemented dietary intervention programme. The limited intervention studies testing the aforementioned hypothesis have used either supplements or pharmaceutical regimens in their treatment protocol and have reported inconsistent findings. More specifically, two studies (Hunter et al. 2000; Chapuy et al. 2002) found no changes in BMD at several skeletal sites (i.e. lumbar spine, femoral neck and total body), as well as in QUS parameters of the calcaneus (i.e. BUA and SOS) after the completion of 1 year of intervention providing supplements of calcium and vitamin $\mathrm{D}_{3}$. Only when supplementation was also followed by supervised weekly exercise sessions were positive changes in lumbar spine BMD and SOS of the heel observed (Engelke et al. 2006). Similar findings to Engelke et al. (2006) have been also reported by intervention studies examining skeletal response to treatment using pharmaceutical regimens (i.e. hormone replacement therapy, biphosphonates, calcitonin), where favourable changes were recorded both for BMD (regional skeletal sites and total body) as well as for QUS parameters of the calcaneus after 1 or more years of treatment (Rosenthall et al. 1999; Frost et al. 2001a). Finally, in a study conducted by Krieg et al. (1999), after providing $1000 \mathrm{mg}$ calcium/d and $20 \mu \mathrm{g}$ vitamin $\mathrm{D}_{3} / \mathrm{d}$, no changes in heel BUA were observed at 12 months, while a significant increase was observed at 24 months.

Based on the aforementioned observations, it has been suggested that more time is required for significant response in QUS parameters to be detected, compared to DXA (Rosenthall et al. 1999). The exact reasons for this are still speculative. To some extent this could be attributed to the fact that QUS parameters also reflect non-mass properties of bone (Hans et al. 1999), which have been suggested to respond more slowly to treatment than BMD (Hans et al. 1998; Gluer, 1999; Rosenthall et al. 1999). Furthermore, the ability of QUS to detect treatment response is not yet well established, mainly due to its lower long-term precision and longitudinal sensitivity (i.e. the ability to monitor skeletal changes over time induced by a specific treatment) compared to DXA (Gluer, 1999). This is also confirmed in the present study, since similarly to other studies (Sahota et al. 2000; Frost et al. 2001a), the long-term precision for QUS parameters was found to range from 1.5 to two times that of legs BMD and from two to three times that of lumbar spine BMD. The present observations indicate that although QUS has a potential role in long-term monitoring of skeletal status changes, the period of time required to follow individual subjects remains 1.5 to three times that for conventional DXA measurements (Sahota et al. 2000).

The current study revealed that the application of a holistic approach combining dietary intervention and consumption of fortified dairy products for a period of 12 months can induce favourable changes in pelvis, total spine and total body BMD of postmenopausal women but not in QUS parameters, which probably require longer intervention periods to reach a significant level. Contrary, no such favourable changes either on BMD or on QUS parameters were obtained in the CaG after supplementation of the recommended calcium dose. The favourable BMD changes observed for the DG might not be solely attributed to the increased intake of calcium and vitamin D but also to other less studied ingredients of dairy products. Recent research has highlighted the important role of potassium, magnesium, vitamin A and other micronutrients (Weinsier \& Krumdieck, 2000) but also of milk protein on bone metabolism (Aoe et al. 2005). It has been suggested that the effect of dairy products on bone health may be more than can be accounted for by any single constituent and that milk ingredients as a whole may be more effective than the sum of its individual parts (Weinsier \& Krumdieck, 2000).

\section{Acknowledgements}

The study was supported by a research grant from Friesland Foods Hellas. The authors would like to thank Ioanna Katsaroli and Paraskevi Kannelou, dietitians, and Sofia Tanagra, technician, for their valuable contribution in data collection and processing.

\section{References}

Aoe S, Koyama T, Toba Y, Itabashi A \& Takada Y (2005) A controlled trial of the effect of milk basic protein (MBP) supplementation on bone metabolism in healthy menopausal women. Osteoporos Int 16, 2123-2128.

Babaroutsi E, Magkos F, Manios Y \& Sidossis LS (2005) Lifestyle factors affecting heel ultrasound in Greek females across different life stages. Osteoporos Int 16, 552-561.

Baeksgaard L, Andersen KP \& Hyldstrup L (1998) Calcium and vitamin D supplementation increases spinal BMD in healthy, postmenopausal women. Osteoporos Int 8, 255-260.

Bauer DC, Gluer CC, Cauley JA, et al. (1997) Broadband ultrasound attenuation predicts fractures strongly and independently of densitometry in older women. A prospective study. Study of Osteoporotic Fractures Research Group. Arch Intern Med 157, 629-634.

Bowen D, Ehret C, Pedersen M, et al. (2002) Results of an adjunct dietary intervention program in the Women's Health Initiative. J Am Diet Assoc 102, 1631-1637. 
Chapuy MC, Pamphile R, Paris E, et al. (2002) Combined calcium and vitamin D3 supplementation in elderly women: confirmation of reversal of secondary hyperparathyroidism and hip fracture risk: the Decalyos II study. Osteoporos Int 13, 257-264.

Chee WS, Suriah AR, Chan SP, Zaitun Y \& Chan YM (2003) The effect of milk supplementation on bone mineral density in postmenopausal Chinese women in Malaysia. Osteoporos Int 14, $828-834$.

Dawson-Hughes B, Harris SS, Krall EA \& Dallal GE (1997) Effect of calcium and vitamin D supplementation on bone density in men and women 65 years of age or older. $N$ Engl J Med 337, 670-676.

Engelke K, Kemmler W, Lauber D, Beeskow C, Pintag R \& Kalender WA (2006) Exercise maintains bone density at spine and hip EFOPS: a 3-year longitudinal study in early postmenopausal women. Osteoporos Int 17, 133-142.

Fogelman I \& Blake GM (2000) Different approaches to bone densitometry. J Nucl Med 41, 2015-2025.

Frost ML, Blake GM \& Fogelman I (2001a) Changes in QUS and BMD measurements with antiresorptive therapy: a two-year longitudinal study. Calcif Tissue Int 69, 138-146.

Frost ML, Blake GM \& Fogelman I (2001b) Quantitative ultrasound and bone mineral density are equally strongly associated with risk factors for osteoporosis. J Bone Miner Res 16, 406-416.

Gluer CC (1997) Quantitative ultrasound techniques for the assessment of osteoporosis: expert agreement on current status. The International Quantitative Ultrasound Consensus Group. J Bone Miner Res 12, 1280-1288.

Gluer CC (1999) Monitoring skeletal changes by radiological techniques. J Bone Miner Res 14, 1952-1962.

Groothausen J, Siemer H, Kemper HCG, Twisk J \& Welten DC (1997) Influence of peak strain on lumbar bone mineral density: an analysis of 15-year physical activity in young males and females. Pediatr Exerc Sci 9, 159-173.

Hans D, Dargent-Molina P, Schott AM, et al. (1996) Ultrasonographic heel measurements to predict hip fracture in elderly women: the EPIDOS prospective study. Lancet 348, 511-514.

Hans D, Njeh CF, Genant HK \& Meunier PJ (1998) Quantitative ultrasound in bone status assessment. Rev Rhum Engl Ed 65, 489-498.

Hans D, Wu C, Njeh CF, et al. (1999) Ultrasound velocity of trabecular cubes reflects mainly bone density and elasticity. Calcif Tissue Int 64, 18-23.

Heaney RP, McCarron DA, Dawson-Hughes B, et al. (1999) Dietary changes favorably affect bone remodeling in older adults. $J \mathrm{Am}$ Diet Assoc 99, 1228-1233.

Hodgson SF, Watts NB, Bilezikian JP, et al. (2003) American Association of Clinical Endocrinologists medical guidelines for clinical practice for the prevention and treatment of postmenopausal osteoporosis: 2001 edition, with selected updates for 2003. Endocr Pract 9, 544-564.

Hunter D, Major P, Arden N, et al. (2000) A randomized controlled trial of vitamin D supplementation on preventing postmenopausal bone loss and modifying bone metabolism using identical twin pairs. J Bone Miner Res 15, 2276-2283.

Institute of Medicine Food and Nutrition Board (2001) Dietary Reference Intakes: Applications in Dietary Assessment. Washington, DC: National Academy Press.

Jackson RD, LaCroix AZ, Gass M, et al. (2006) Calcium plus vitamin D supplementation and the risk of fractures. $N$ Engl J Med 354, 669-683.

Krieg MA, Jacquet AF, Bremgartner M, Cuttelod S, Thiebaud D \& Burckhardt P (1999) Effect of supplementation with vitamin D3 and calcium on quantitative ultrasound of bone in elderly institutionalized women: a longitudinal study. Osteoporos Int 9, 483-488.
Lau EM, Lynn H, Chan YH \& Woo J (2002) Milk supplementation prevents bone loss in postmenopausal Chinese women over 3 years. Bone 31, 536-540.

McClung MR, Wasnich RD, Hosking DJ, et al. (2004) Prevention of postmenopausal bone loss: six-year results from the Early Postmenopausal Intervention Cohort Study. J Clin Endocrinol Metab 89, 4879-4885.

Magkos F, Manios Y, Babaroutsi E \& Sidossis LS (2005) Quantitative ultrasound calcaneus measurements: normative data for the Greek population. Osteoporos Int 16, 280-288.

Meier C, Woitge HW, Witte K, Lemmer B \& Seibel MJ (2004) Supplementation with oral vitamin D3 and calcium during winter prevents seasonal bone loss: a randomized controlled open-label prospective trial. J Bone Miner Res 19, 1221-1230.

National Research Council (1986) Nutrient Adequacy: Assessment Using Food Consumption Surveys. Report of the Food and Nutrition Board. Washington, DC: National Academy of Sciences.

Njeh CF (1999) Quantitative Ultrasound: Assessment of Osteoporosis and Bone Status. London: Dunitz.

Palacios S, Castelo-Branco C, Cifuentes I, et al. (2005) Changes in bone turnover markers after calcium-enriched milk supplementation in healthy postmenopausal women: a randomized, doubleblind, prospective clinical trial. Menopause 12, 63-68.

Pinheiro MM, Castro CH, Frisoli A Jr \& Szejnfeld VL (2003) Discriminatory ability of quantitative ultrasound measurements is similar to dual-energy X-ray absorptiometry in a Brazilian women population with osteoporotic fracture. Calcif Tissue Int 73, 555-564.

Prince R, Devine A, Dick I, et al. (1995) The effects of calcium supplementation (milk powder or tablets) and exercise on bone density in postmenopausal women. J Bone Miner Res 10, 1068-1075.

Reid IR, Ames RW, Evans MC, Gamble GD \& Sharpe SJ (1995) Long-term effects of calcium supplementation on bone loss and fractures in postmenopausal women: a randomized controlled trial. Am J Med 98, 331-335.

Riggs BL, O'Fallon WM, Muhs J, O'Connor MK, Kumar R \& Melton LJ 3rd (1998) Long-term effects of calcium supplementation on serum parathyroid hormone level, bone turnover, and bone loss in elderly women. J Bone Miner Res 13, 168-174.

Rosenthall L, Caminis J \& Tenehouse A (1999) Calcaneal ultrasonometry: response to treatment in comparison with dual x-ray absorptiometry measurements of the lumbar spine and femur. Calcif Tissue Int 64, 200-204.

Sahota O, San P, Cawte SA, Pearson D \& Hosking DJ (2000) A comparison of the longitudinal changes in quantitative ultrasound with dual-energy X-ray absorptiometry: the four-year effects of hormone replacement therapy. Osteoporos Int 11, 52-58.

Storm D, Eslin R, Porter ES, et al. (1998) Calcium supplementation prevents seasonal bone loss and changes in biochemical markers of bone turnover in elderly New England women: a randomized placebo-controlled trial. J Clin Endocrinol Metab 83, 3817-3825.

Trichopoulou A (2004) Composition Tables of Foods and Greek Dishes. Athens: Department of Hygiene and Epidemiology, School of Medicine.

University of Crete (1991) Food Composition Tables. nutrition.med.uoc.gr/GreekTables.

Weinsier RL \& Krumdieck CL (2000) Dairy foods and bone health: examination of the evidence. Am J Clin Nutr 72, 681-689.

Wolff I, van Croonenborg JJ, Kemper HC, Kostense PJ \& Twisk JW (1999) The effect of exercise training programs on bone mass: a meta-analysis of published controlled trials in pre- and postmenopausal women. Osteoporos Int 9, 1-12.

Wu XP, Liao EY, Huang G, Dai RC \& Zhang H (2003) A comparison study of the reference curves of bone mineral density at different skeletal sites in native Chinese, Japanese, and American Caucasian women. Calcif Tissue Int 73, 122-132. 